Full Paper

\title{
On the Electrochemical Oxidation of Resveratrol
}

\author{
Oana Corduneanu, Patricia Janeiro, Ana Maria Oliveira Brett* \\ Departamento de Quimica, Faculdade de Ciencias e Tecnologia, Universidade de Coimbra, 3004-535 Coimbra, Portugal \\ *e-mail: brett@ci.uc.pt
}

Received: December 13, 2005

Accepted: February 08, 2006

\begin{abstract}
Resveratrol (3,5,4'-trihydroxystilbene) is an organic metabolite produced by plants in response to fungal infection. It is found in various plant fruits and is abundant in the skins of unripe grapes and related products. This photosensitive molecule exists in two isomeric forms, trans and cis-resveratrol. The antioxidant activity of resveratrol, both trans and cis forms, was evaluated by means of cyclic, differential pulse and square-wave voltammetry over a wide $\mathrm{pH}$ range, using a glassy carbon electrode. Voltammograms of resveratrol presented two oxidation peaks; the first oxidation peak corresponds to the oxidation of the phenol group and was shown to undergo an irreversible oxidation reaction. The second oxidation peak corresponds to the oxidation of the resorcinol moiety and is also irreversible. The influence of $\mathrm{pH}$ on the electrochemical oxidation process of resveratrol was investigated.
\end{abstract}

Keywords: trans-Resveratrol, cis-Resveratrol, Electrochemistry, pH dependent antioxidant activity

DOI: 10.1002/elan.200503469

\section{Introduction}

Resveratrol (3,5,4'-trihydroxy-trans-stilbene) is a naturally occurring phytoalexin produced by a limited number of plants as a response to stress or injury, fungal attack or UV exposure $[1,2]$. It can be found in vines, eucalyptus, some pines and berries, in the roots of the Asian medicinal plant Polygonum cuspidatum [3], grapes, peanuts and their derived products.

Various studies reported resveratrol to have anticancer activity $[4,5]$, to prevent heart and blood diseases, to be a neuroprotective agent $[6,7]$, hormone [8], gene and enzyme modulator [9], and possibly to be a longevity activator [10]. Being a phenolic compound, it may act as an antioxidant that can protect cell membranes and cellular DNA from the damaging effects of free radical induced oxidation [11].

Resveratrol exists as trans- and cis-isomers (Scheme 1) and both isomeric forms have been detected in wines [12], with their concentration in a direct relationship to the<smiles>Oc1ccc(/C=C/c2cc(O)cc(O)c2)cc1</smiles>

trans-resveratrol weather conditions [1-3]. Physiologically, the cis- form seems to act in the same way as trans-resveratrol, although it is less effective [13].

Electrochemical measurements leading to the quantification and determination of physicochemical parameters of antioxidants are relevant for the evaluation of the antioxidative properties of polyphenols [14]. In order to act as an antioxidant, resveratrol itself has to undergo oxidation. In a scavenging reaction a hydrogen atom is donated to the radical that becomes a nonradical. The hydrogen atoms are supplied by dissociation of the $-\mathrm{OH}$ groups, a process that takes place both in scavenging reactions and electrochemical oxidation. Because the hydroxyl groups are electron donating, the phenoxyl radicals are preferred targets for the oxidants, but they may also form polymeric products that adsorb on the surface of the electrode $[15,16]$.

Solid state voltammetry consists in mechanically immobilizing microparticles of resveratrol onto the glassy carbon surface. Abrasive stripping voltammetry can be employed

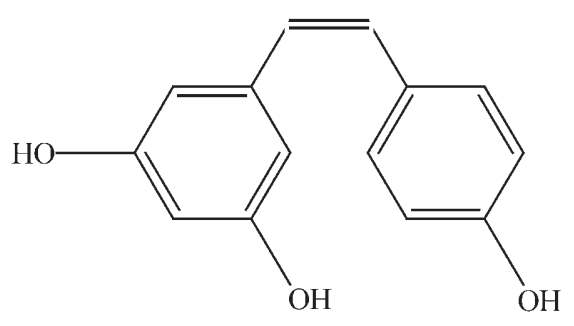

cis-resveratrol

Scheme 1. Molecular structure of resveratrol trans- and cis-isomers. 
for a direct study of solid samples that contain electrochemically active elements $[17-20]$. This method was used for an initial characterization of resveratrol electrochemical oxidation properties. The main disadvantage of this technique is the impossibility to know the amount of immobilized compound and therefore its concentration.

The mechanism of electrochemical oxidation of resveratrol, in the trans-and cis-configurations has been studied at a glassy carbon electrode using cyclic, differential pulse and square-wave voltammetry over a wide range of $\mathrm{pH}$.

\section{Experimental}

\subsection{Reagents}

Resveratrol $\mathrm{C}_{14} \mathrm{H}_{12} \mathrm{O}_{2}$ (3,5,4'-trihydroxystilbene) was purchased from Extrasynthèse, Genay, France and all the other reagents were Merck analytical grade. All the solutions were prepared with high-purity deionized water from a Millipore Milli-Q purification system (resistivity $\geq 18 \mathrm{M} \Omega / \mathrm{cm}$ ).

A stock solution of resveratrol, $4.4 \times 10^{-3} \mathrm{M}$, was prepared in ethanol and kept at $-4{ }^{\circ} \mathrm{C}$. This solution was diluted to the desired concentration by mixing buffer supporting electrolyte.

Solutions of buffer supporting electrolyte of ionic strength $0.2 \mathrm{M}$ were used in all experiments (see Table 1), and were prepared using analytical grade reagents and purified water from a Millipore Milli-Q system.

\subsection{Instrumentation}

The electrochemical experiments were done using a $\mu$ Autolab type II PGSTAT running with GPES (General Purpose Electrochemical System) version 4.9 software PG (EcoChemie, Utrecht, The Netherlands).

Voltammograms were recorded using a three-electrode configuration (Cypress System, Inc., USA). The working electrode was a glassy carbon electrode (GCE) of $1.5 \mathrm{~mm}$ diameter; $\mathrm{Ag} / \mathrm{AgCl}$ (saturated $\mathrm{KCl}$ ) was used as a reference

Table 1. Supporting electrolyte solutions $0.2 \mathrm{M}$ ionic strength.

\begin{tabular}{|c|c|}
\hline Composition & $\mathrm{pH}$ \\
\hline $0.2 \mathrm{M} \mathrm{HCl}+0.2 \mathrm{M} \mathrm{KCl}$ & 1.2 \\
\hline $0.2 \mathrm{M} \mathrm{HCl}+0.2 \mathrm{M} \mathrm{KCl}$ & 2.1 \\
\hline $0.2 \mathrm{M} \mathrm{NaAcO}+0.2 \mathrm{M} \mathrm{HAcO}$ & 3.2 \\
\hline $0.2 \mathrm{M} \mathrm{NaAcO}+0.2 \mathrm{M} \mathrm{HAcO}$ & 3.9 \\
\hline $0.2 \mathrm{M} \mathrm{NaAcO}+0.2 \mathrm{M} \mathrm{HAcO}$ & 5.1 \\
\hline $0.2 \mathrm{M} \mathrm{Na}_{2} \mathrm{HPO}_{4}+0.2 \mathrm{M} \mathrm{NaH}_{2} \mathrm{PO}_{4}$ & 5.9 \\
\hline $0.2 \mathrm{M} \mathrm{Na}_{2} \mathrm{HPO}_{4}+0.2 \mathrm{M} \mathrm{NaH}_{2} \mathrm{PO}_{4}$ & 7.0 \\
\hline $0.2 \mathrm{M} \mathrm{Na}_{2} \mathrm{HPO}_{4}+0.2 \mathrm{M} \mathrm{NaH}_{2} \mathrm{PO}_{4}$ & 8.2 \\
\hline $2 \mathrm{M} \mathrm{NH}_{4} \mathrm{Cl}+2 \mathrm{M} \mathrm{NH}_{3}$ & 9.2 \\
\hline $2 \mathrm{M} \mathrm{NH}_{4} \mathrm{Cl}+2 \mathrm{M} \mathrm{NH}_{3}$ & 10.3 \\
\hline $0.2 \mathrm{M} \mathrm{KCl}+0.2 \mathrm{M} \mathrm{NaOH}$ & 11.0 \\
\hline $0.2 \mathrm{M} \mathrm{KCl}+0.2 \mathrm{M} \mathrm{NaOH}$ & 11.9 \\
\hline
\end{tabular}

electrode and a platinum wire as a counter electrode. The electrodes were used in an electrochemical cell of $2 \mathrm{~mL}$ capacity.

UV measurements were performed with an UV-VIS Spectrophotometer SPECORD S100 running with Aspect Plus Version 1.5 (Analytik Jena GmbH, Jena, Germany).

The $\mathrm{pH}$ measurements were carried out with a CRISON GLP $21 \mathrm{pH}$-meter at room temperature.

\subsection{Procedure}

All experiments were performed at room temperature (ca. $23 \pm 2{ }^{\circ} \mathrm{C}$ ) and in the presence of oxygen.

The solid-state electrochemistry of resveratrol was performed by attaching the aqueous insoluble solid to the surface of the working electrode by mechanical pressing.

Measurements in solution were carried out after diluting the resveratrol ethanol stock solution to the desired concentration by mixing buffer supporting electrolyte.

Cyclic voltammograms were recorded at scan rates of 25, 50 and $100 \mathrm{mV} \mathrm{s}^{-1}$. The differential pulse voltammetry conditions were: pulse amplitude $50 \mathrm{mV}$, pulse width $70 \mathrm{~ms}$ and scan rate of $5 \mathrm{mV} \mathrm{s}$. Square-wave voltammetry conditions were: frequencies of 13,25 and $50 \mathrm{~Hz}$, amplitude $50 \mathrm{mV}$ and a potential increment of $2 \mathrm{mV}$ (effective scan rates of 25,50 and $100 \mathrm{mV} \mathrm{s}^{-1}$, respectively). A current response was recorded in the range -1.0 to $+1.35 \mathrm{~V}$. All potentials were reported vs. $\mathrm{Ag} / \mathrm{AgCl}$ (sat $\mathrm{KCl}$ ) electrode.

The glassy carbon working electrode was polished with diamond spray ( 3 and $1 \mu \mathrm{m})$ prior to each measurement and abundantly washed with deionized water.

\section{Results and Discussion}

\subsection{Solid State Electrochemistry}

The resveratrol molecule contains both resorcinol and phenol moieties. Because of the conjugated double bond between these, resveratrol has a planar structure (Scheme 1). All three functional $-\mathrm{OH}$ groups attached to the ring structures are electroactive.

Abrasive stripping voltammetry was done by mechanical immobilization of microparticles of trans-resveratrol onto the surface of the working electrode followed by immersion in electrolyte solution. Since the microcrystals of resveratrol are insoluble in water after mechanical pressing they remain attached to the electrode surface [17]. The measurements were carried out in the dark in order to ensure only the presence of the trans- isomer.

Cyclic voltammograms of trans-resveratrol at $\mathrm{pH} 3.2$ showed the presence of two oxidation peaks associated with the two moieties of the molecule. Both peaks, $\mathrm{P}_{1}$ at $+0.65 \mathrm{~V}$ and $\mathrm{P}_{2}$ at $+0.92 \mathrm{~V}$, are irreversible. The second scan shows the absence of both oxidation peaks probably due to the formation of a non-electroactive film on the surface of the electrode, Figure 1. 
Both oxidation processes of resveratrol, observed using solid state cyclic voltammetry, are affected by the $\mathrm{pH}$ of the buffer aqueous solution, Figure 2, the peak potentials being displaced to more negative potentials with increasing $\mathrm{pH}$ values.

Square-wave voltammetry is a fast, low-consumption technique that can be employed with success for the examination of the solid electroactive species [21, 22]. The irreversibility of both peaks was confirmed over the whole $\mathrm{pH}$ range by solid state square-wave voltammetry measurements of mechanically attached resveratrol. The total current response shows two peaks with potentials close to those obtained by cyclic voltammetry, Figure 3 . The starting potential was at $+0.2 \mathrm{~V}$ for $\mathrm{pH} 3.2$ acetate buffer and the

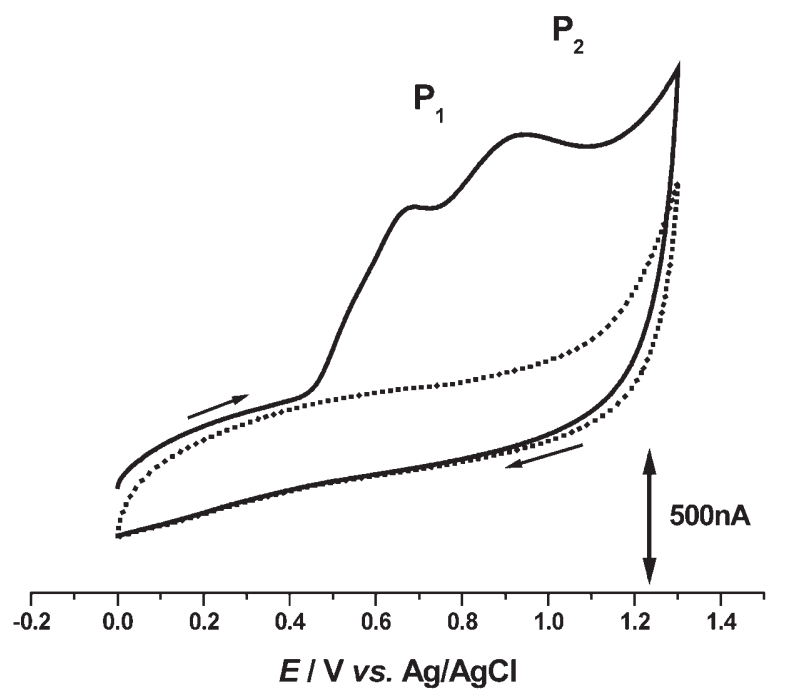

Fig. 1. Solid state cyclic voltammograms of trans-resveratrol in pH 3.2, $0.2 \mathrm{M}$ acetate buffer solution: (-) first and (.....) second scan. Scan rate: $25 \mathrm{mV} \mathrm{s}^{-1}$.

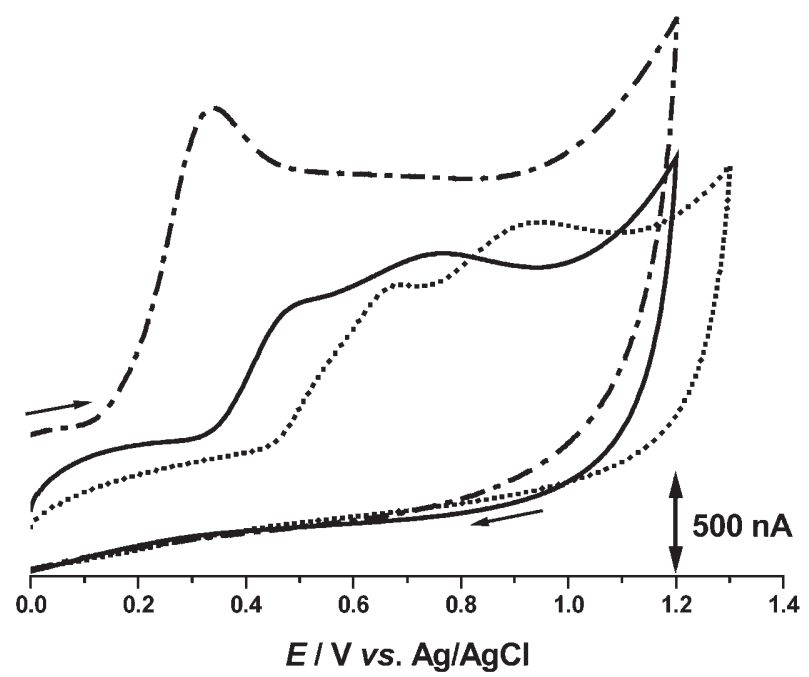

Fig. 2. Solid state cyclic voltammograms of trans-resveratrol in different buffer solutions: $(\cdot \cdots \cdot.) \mathrm{pH} 3.2,(-) \mathrm{pH} 7.0$, and $(\cdot \cdot \cdot)$ $\mathrm{pH}$ 11.9. Scan rate: $25 \mathrm{mV} \mathrm{s}^{-1}$.

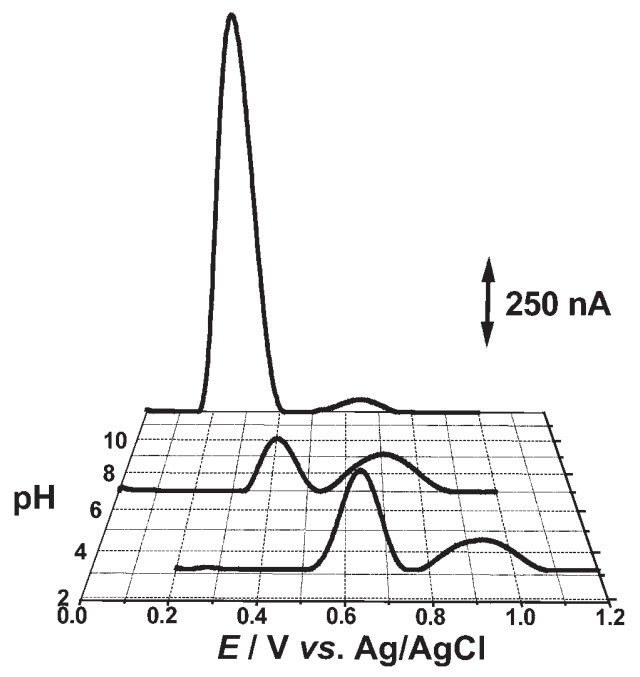

Fig. 3. 3D plot of solid state square-wave voltammograms of trans-resveratrol in different buffer solutions. Effective scan rate: $25 \mathrm{mVs}^{-1}$.

frequency was $13 \mathrm{~Hz}$, which corresponds to an effective scan rate of $25 \mathrm{mV} \mathrm{s}^{-1}$. The forward scan clearly shows the presence of both oxidation peaks and the lack of backward current the behavior of an irreversible reaction.

\subsection{Measurements of Resveratrol in Solution}

Spectrophotometric and voltammetric measurements of resveratrol in a mixed ethanol/buffer solution were performed in order to complement the data obtained by solid state electrochemistry.

\subsubsection{Spectrophotometric Measurements}

The solution of trans-resveratrol was prepared and protected from light to avoid photon-induced isomerization and the voltammetric measurements were performed initially in the dark. UV spectra recorded after each set of electrochemical measurements confirmed the presence of only the trans- isomer. The UV spectrum exhibits two maxima at $306 \mathrm{~nm}$ and $320 \mathrm{~nm}$, which are characteristic of the transisomer. The solution was then exposed to diffuse daylight for $8-10$ h so the photo-isomerization occurred and a new UV spectrum was recorded, showing a maximum around $290 \mathrm{~nm}$, characteristic of the cis- isomer, as reported in the literature [23].

\subsubsection{Voltammetry of trans-Resveratrol and cis-Resveratrol}

Differential pulse voltammograms were recorded for different pHs (Table 1) to confirm the dependence of the oxidation mechanism of resveratrol with $\mathrm{pH}$. In all buffer solutions the voltammograms showed the presence of two oxidation peaks, as obtained by solid-state voltammetry. The oxidation of the phenol moiety occurs first, at a potential below $+0.7 \mathrm{~V}$ depending on $\mathrm{pH}$ and corresponds 
to peak $\mathrm{P}_{1}$. The resorcinol group is oxidized at higher positive potentials, but below $+0.9 \mathrm{~V}$, depending on $\mathrm{pH}$ and corresponds to peak $\mathrm{P}_{2}$.

It can be observed in Figure 4a that a peak $\mathrm{P}_{3}$ appeared at $+0.94 \mathrm{~V}$, in $\mathrm{pH} 3.2$ acetate buffer. The oxidation peak current for both peaks decreased in the second scan, due to the adsorption of the oxidation products at the electrode surface, which are oxidized at $+0.40 \mathrm{~V}$, peak $\mathrm{P}_{4}$.

A differential pulse voltammogram of resveratrol at pH 3.2 was recorded, where the scan was stopped at $+0.65 \mathrm{~V}$, immediately after peak $\mathrm{P}_{1}$. The subsequent scans, recorded in the same conditions, showed the absence of any peaks related to the oxidation products of resveratrol.

Control measurements with resorcinol at $\mathrm{pH} 3.2$ show only one peak in the first scan at $+0.82 \mathrm{~V}$, at almost the same potential as the peak $\mathrm{P}_{2}$ of resveratrol, Figure $4 \mathrm{~b}$. In the second scan of resorcinol a peak appears, at $+0.45 \mathrm{~V}$, due to the oxidation of resorcinol oxidation products formed in the first scan.

These control experiments led to the conclusion that peak $\mathrm{P}_{2}$ is due to the oxidation of the resorcinol moiety of resveratrol and that peak $\mathrm{P}_{4}$ formed in the second scan is related to further oxidation of this oxidation product.

The peak $\mathrm{P}_{3}$ of resveratrol only occurs in acid media and was not observed in the control measurements with resorcinol for the same $\mathrm{pH}$. This behavior was exhibited by both trans- and cis-isomers, Figure $4 \mathrm{c}$. For increasing $\mathrm{pH}$ values, peak $\mathrm{P}_{3}$ diminishes and remains only as a small shoulder of $\mathrm{P}_{2}$ over the rest of the $\mathrm{pH}$ range studied. The occurrence of peak $\mathrm{P}_{3}$ can be explained by the rearrangement of the molecule of resveratrol, parallel and perpendicular on the electrode surface, due to the presence of the double bond between the phenol and resorcinol moieties, which leads to different oxidation potentials of the two hydroxyl groups presented by the resorcinol moiety.
Baseline-corrected differential pulse voltammograms of trans-resveratrol as a function of $\mathrm{pH}$, Figure 5, show a decrease of the oxidation potentials with increasing $\mathrm{pH}$. It was also observed that peak $\mathrm{P}_{1}$ gives higher currents in basic media, whereas for peak $\mathrm{P}_{2}$ the currents were higher in acid and neutral media. The number of electrons involved in the oxidation process, using the relation of peak width at half height [24], was determined to be $1 \mathrm{e}^{-}$for peak $\mathrm{P}_{1}$ and $2 \mathrm{e}^{-}$for $\mathrm{P}_{2}$, over the whole $\mathrm{pH}$ range studied.

The same study was done for cis-resveratrol and only a small difference was observed in the peak potentials which is not sufficient to allow a distinction between trans- and cisisomers by means of electrochemistry, Figure 6. The relation between the oxidation potential $E_{\mathrm{p}}$ and $\mathrm{pH}$ is linear with a slope of $-45 \mathrm{mV}$ per $\mathrm{pH}$ unit for peak $\mathrm{P}_{1}$, for both trans- and

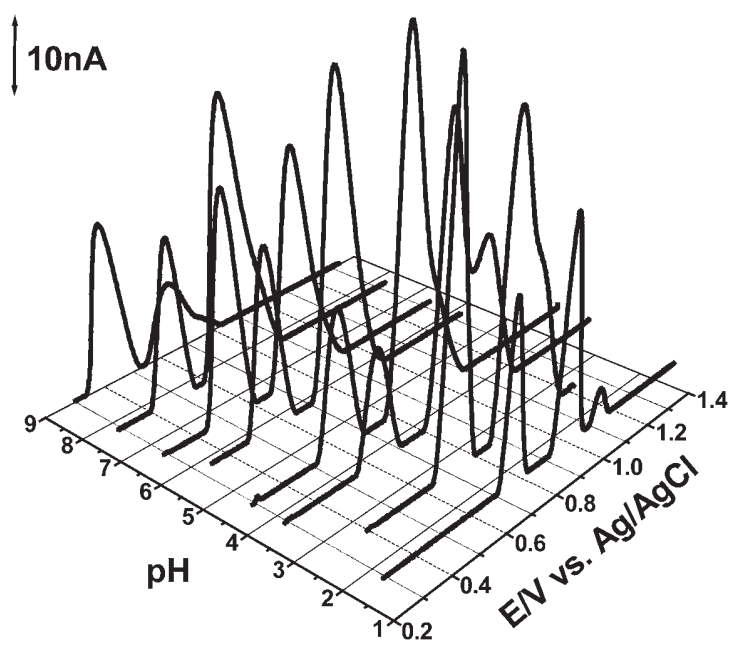

Fig. 5. 3D plot of differential pulse voltammograms of $10 \mu \mathrm{M}$ trans-resveratrol in ethanol/buffer supporting electrolyte as a function of $\mathrm{pH}$. Scan rate: $5 \mathrm{mV} \mathrm{s}^{-1}$.
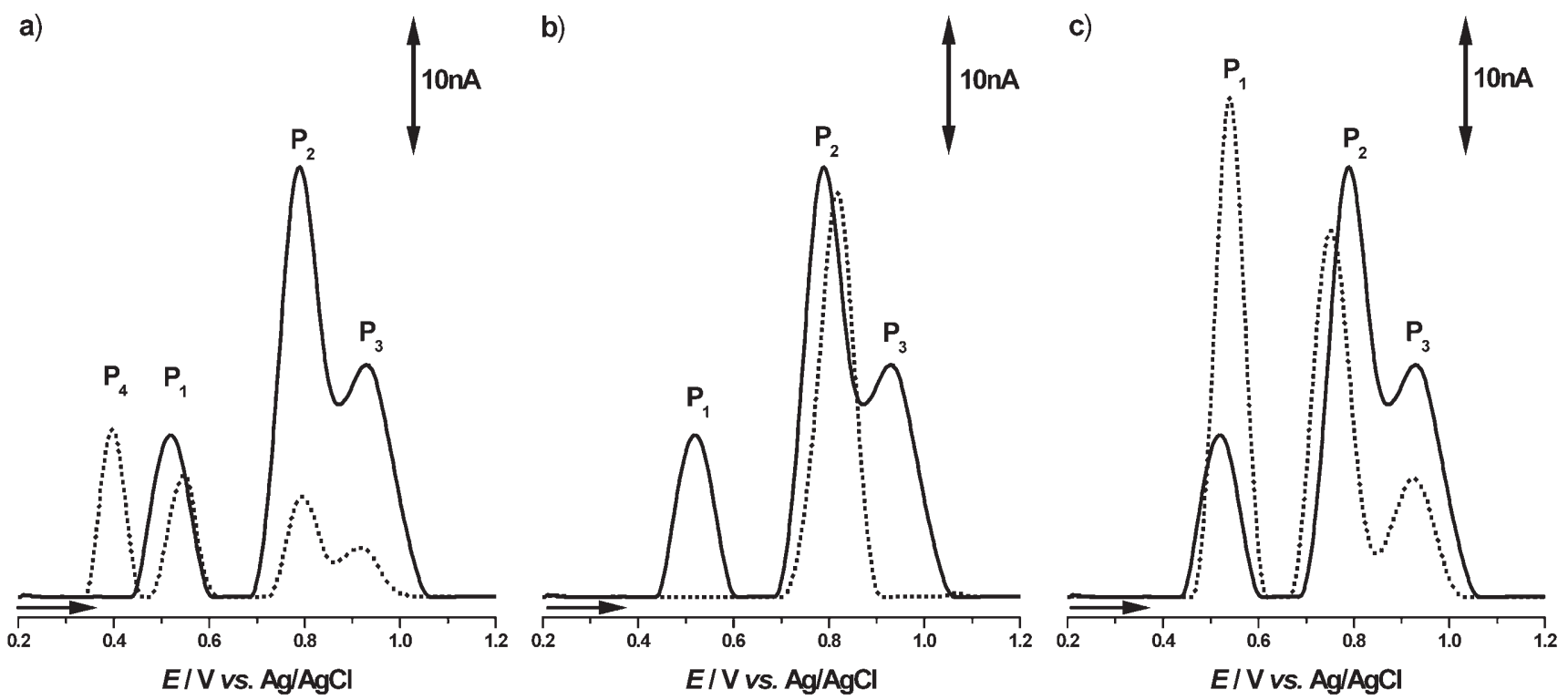

Fig. 4. Baseline-corrected differential pulse voltammograms of $10 \mu \mathrm{M}$ trans-resveratrol (一) first scan and (.....): a) second scan, b) $10 \mu \mathrm{M}$ resorcinol, c) $10 \mu \mathrm{M}$ cis-resveratrol. Scan rate: $5 \mathrm{mV} \mathrm{s}^{-1}$, in ethanol/pH $3.20 .2 \mathrm{M}$ acetate buffer solution. 


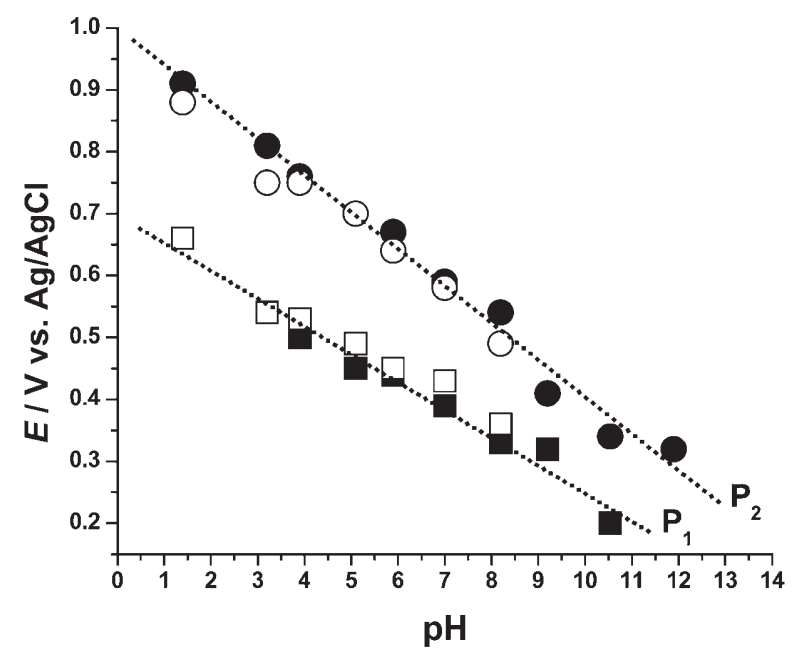

Fig. 6. Dependence of differential pulse potentials on $\mathrm{pH}$ of trans- and cis-resveratrol in ethanol/buffer supporting electrolyte: trans-resveratrol $\left(\mathbf{-}, \mathrm{P}_{1}\right)$ peak 1 and $\left(\bullet, \mathrm{P}_{2}\right)$ peak 2 , and cisresveratrol $\left(\square, \mathrm{P}_{1}\right)$ peak 1 and $\left(\circ, \mathrm{P}_{2}\right)$ peak 2 .

cis-resveratrol, probably due to a possible dimer formation. For peak $\mathrm{P}_{2}$ a slope of $-59 \mathrm{mV}$ per $\mathrm{pH}$ unit was found, leading to the conclusion that during the oxidation process protons are also released from the molecule, corresponding to a mechanism with the same number of protons and electrons.

\subsection{Analytical Determination of Resveratrol}

For the analytical determination of resveratrol the oxidation peak $\mathrm{P}_{1}$ was chosen, since it occurs at low oxidation potentials.

Differential pulse voltammograms were recorded for standard additions of resveratrol corresponding to bulk concentrations between 0.3 and $41 \mu \mathrm{M}$ resveratrol in ethanol/pH 7.0 0.2 M phosphate buffer. After each measurement the electrode surface was polished and thoroughly rinsed with deionized water in order to ensure a clean GCE surface. Differential pulse voltammograms obtained for different concentrations of resveratrol are shown in Figure 7 curves a-d.

For each concentration three measurements were performed. Good linearity was found between peak current and concentration described by the equation: $I_{\mathrm{pc}}(\mathrm{A})=3.93 \times$ $10^{-9}+9.03 \times 10^{-3}$ [trans-resveratrol $](\mathrm{M})$, where $R=0.99$, $N=9, P<0.0001$ and $S D=4.86 \times 10^{-10}$. The parameters to define the sensitivity were calculated and the value obtained for the limit of detection, $L O D=1.78 \times 10^{-7} \mathrm{M}$, was based on three times the noise level, and the limit of quantification was $L O Q=5.86 \times 10^{-6}$, based on ten times the noise level.

\section{Conclusions}

The present voltammetric study aimed to characterize the electrochemical properties of resveratrol, a compound of

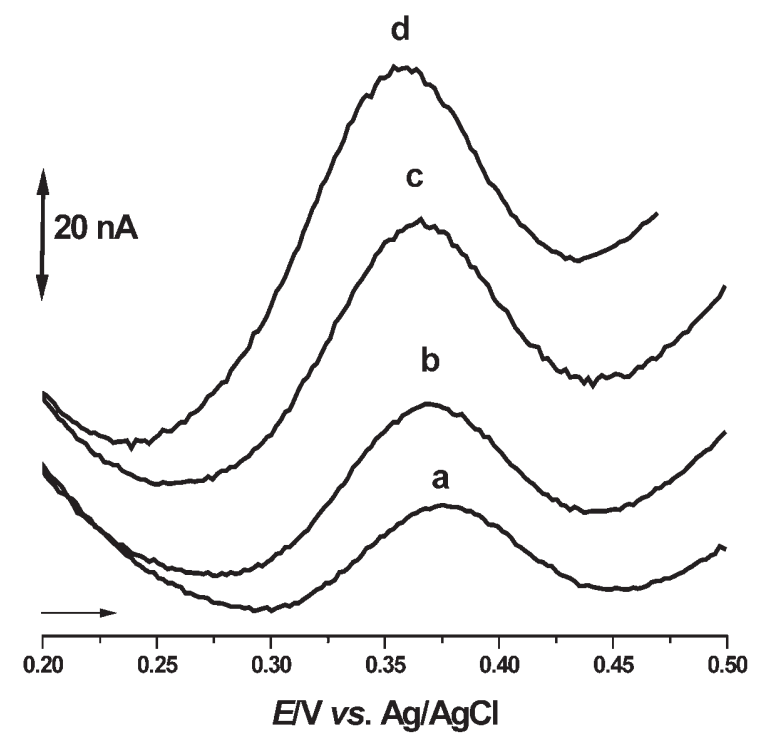

Fig. 7. Differential pulse voltammograms in ethanol/pH 7.0 $0.2 \mathrm{M}$ phosphate buffer solution: a) 1.5, b) 2, c) 3 and d) $5 \mu \mathrm{M}$ trans-resveratrol. Scan rate $5 \mathrm{mV} \mathrm{s}^{-1}$.

great interest mainly because of its presence in red wines and for its potential medical benefits.

The oxidation process of resveratrol is complex, $\mathrm{pH}$ dependent, all steps being irreversible. Resveratrol presents two oxidation peaks corresponding to its oxidizable moieties, a phenol and a resorcinol. From the point of view of free radical chemistry, resveratrol is a moderate antioxidant with relatively high oxidation potentials, which depend on the $\mathrm{pH}$ of the buffer supporting electrolyte. Resveratrol adsorbs strongly on the electrode surface and the final oxidation products block the electrode surface, as shown by the decrease of all oxidation peaks in successive scans.

Also, it has been shown that there is no appreciable difference in oxidation potentials between the trans- and the cis- forms of resveratrol which would allow an electrochemical identification of the isomers.

\section{Acknowledgements}

Financial support from Fundação para a Ciência Tecnologia (FCT), Ph.D. Grant SFRH/BD/18914/2004 (O.C.), POCTI (cofinanced by the European Community Fund FEDER), ICEMS (Research Unit 103), and European Project HPRNCT-2002-00186 is gratefully acknowledged.

\section{References}

[1] P. Langcake, R. J. Pryce, Phytochemistry 1977, 16, 1193.

[2] G. J. Soleas, E. P. Diamandis, D. M. Goldberg, Clin. Biochem. 1997, 30, 91.

[3] E. H. Siemann, L. L. Creasy, Amer. J. Enol. Vitic. 1992, 43, 49.

[4] J. F. Savouret, M. Quesne, Biomed. Pharmacother. 2002, 56, 84. 
[5] B. Jannin, M. Menzel, J.-P. Berlot, D. Delmas, A. Lançon, N. Latruffe, Biochem. Pharmacol. 2004, 68, 1113.

[6] N. C. Kaneider, B. Mosheimer, N. Reinisch, J. R. Patsch, C. J. Wiedermann, Thrombosis Research 2004, 114, 185.

[7] U. Kiziltepe, N. D. Turan, U. Han, A. T. Ulus, F. Akar, J. Vascular Surgery 2004, 40, 138.

[8] T. Cornwell, W. Cohick, I. Raskin, Phytochem. 2004, 65, 995.

[9] B. A. Narayanan, N. K. Narayanan, G. G. Re, D. W. Nixon, Int. J. Cancer 2003, 104, 204.

[10] S. Jarolim, J. Millen, G. Herren, P. Laun, D. S. Goldfarb, M. Breitenbach, FEMS Yeast Res. 2004, 5, 169.

[11] M. Fontecave, M. Lepoivre, E. Elleingand, C. Gerez, O. Guittet, FEBS Lett. 1998, 421, 277.

[12] D. M. Goldberg, E. Ng, A. Karumanchiri, J. Yan, E. P. Diamandis, G. Soleas, J. Chromatogr. A, 1995, 708, 89.

[13] J.-P. Balsy, F. Marre-Fournier, J.-C. Le Bail, G. Habrioux, A. J. Chulia, Life Sci. 2000, 66, 769.
[14] H. Hotta, H. Sakamoto, S. Nagano, T. Osakai, Y. Tsujino, Biochim. Biophys. Acta 2001, 1526, 159.

[15] M. Filipiak, Anal. Sci. 2001, 17, i1667.

[16] S. V. Jovanovic, S. Steenken, Y. Hara, M. G. Simic, J. Chem. Soc. Perkin Trans. 1996, 2, 2497.

[17] F. Scholz, B. Meyer, Chem. Soc. Rev. 1994, 23, 341.

[18] M. Lovric, F. Scholz, J. Solid State Electrochem. 1997, 1, 108.

[19] A. M. Bond, J. Solid State Electrochem. 1997, 1, 185.

[20] S. Komorsky-Lovric, V. Mirceski, F. Scholz, Mikrochim. Acta 1999, 132, 67.

[21] P. Janeiro, A. M. Oliveira Brett, Electroanalysis 2005, 17, 733.

[22] A. M. Oliveira Brett, L. A. da Silva, H. Fujii, S. Mataka, T. Thienmann, J. Electroanal. Chem. 2003, 549, 91.

[23] I. Kolouchova-Hanzlikova, K. Melzoch, V. Filip, J. Smidrkal, Food Chem. 2004, 87, 151.

[24] C. M. A. Brett, A. M. Oliveira Brett, Electrochemistry: Principles, Methods and Applications, Oxford Science Publications, Oxford 1993.

\section{The definitive work in electrochemistry}

\section{Encyclopedia of Electrochemistry}

Available Volumes:

1: Thermodynamics and Electrified Interfaces

2: Interfacial Kinetics and Mass Transport

3: Instrumentation and Electroanalytical Chemistry

4: Corrosion and Oxide Films

6: Semiconductor Electrodes and Photoelectrochemistry

8: Organic Electrochemistry

9: Bioelectrochemistry

Forthcoming Volumes (completed Fall 2006):

5: Electrochemical Engineering

7: Inorganic Electrochemistry

10: Modified Electrodes

11: Index

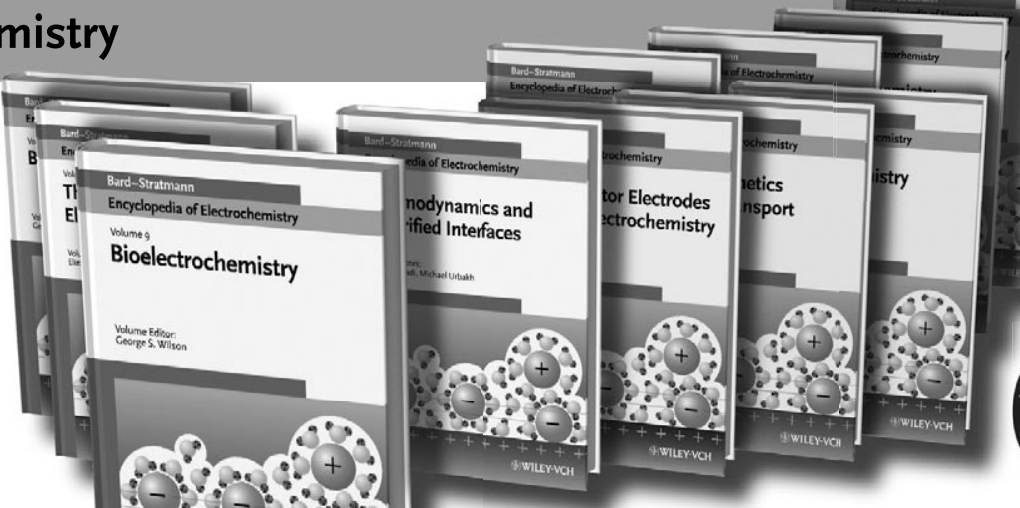

2006. Approx 6000 pages with approx 3000 figures and about 1000 tables. Hardcover. ISBN 3-527-30250-6 $€ 299.00 * / £ 200.00$ per volume. *The $€$-price is valid for Germany only!

Editors-in-Chief: Allen J. Bard, Department of Chemistry, University of Texas, Austin, USA/ Martin Stratmann, Max Planck-Institute for Iron Research, Duesseldorf, Germany

Stay up-to-date in electrochemistry

- a total of 11 volumes makes this the first and only complete reference on electrochemistry

- covering all aspects, from fundamental research to applications in industry

$\overrightarrow{b_{0}}$ easy access to electrochemical topics

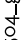

www.wiley-vch.de/bard/eoe

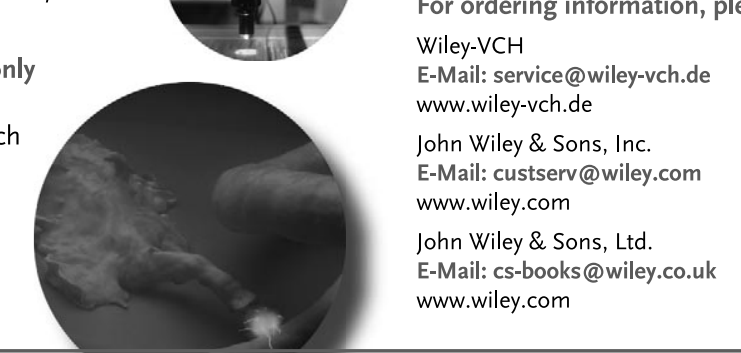

11 volumes (including index volume)

For ordering information, please contact our customer service: Wiley-VCH www.wiley-vch.de

WILEY-VCH WILEY

(i) WILEY E-Mail: cs-books@wiley.co.uk
www.wiley.com 